\title{
Leder religionsantropologins utmaningar och forskningsproblematik till nostalgiska elegier och idylliska tankar om ädla vildar?
}

\author{
Svar på Anders Klostergaard Petersens review af Michael \\ Rothstein, Regnskovens religion (2016)
}

ANNE-CHRISTINE HORNBORG

ENGLISH ABSTRACT: Theology, religious studies, the history of religion, and the anthropology of religion have different histories as research disciplines, which explains differences in how they pose research problems and define their research fields. In some respects, the disciplines have a lot in common and may cross-fertilize each other. In this article, I reflect on a theologian's critical review in Religionsvidenskabeligt Tidsskrift 67 (2018) of a text applying the approach of the anthropology of religion, in order to highlight some of the issues and perspectives that distinguish the two fields. Much of the theological critique appears to derive from a lack of familiarity with the situations, contexts, and discussions that an anthropologist of religion may encounter. My focus is thus on topics such as engaged anthropology, reflexivity, culture contact, modernity, and power relations.

SVENSK RESUME: Teologi, religionsvetenskap, religionshistoria och religionsantropologi bär på olika historia i sina framväxter som forskarämnen, och därmed kan olika problemställningar och forskningsfält vara aktuella. I vissa fall delar ämnena också mycket och kan befrukta varandra. Jag vill dock i denna artikel utgå från en teologs kritiska review $i$ Religionsvidenskabeligt Tidsskrift 67 (2018) av en religionsantropologisk text för att visa på några av de frågor som skiljer sig åt. Mycket av den teologiska kritiken kan finnas $i$ en brist på kännedom att tackla de situationer, kontexter och diskussioner som en religionsantropolog kan hamna i. Fokus kommer därför att vara ämnen som engagerad antropologi, reflexivitet, kulturmöten, modernitet och maktrelationer. 
KEYWORDS: Hunter-Gatherer Religion; Penan; Anthropology of Religion; Engaged anthropology; Reflexivity; Culture Contacts; Michael Rothstein

Teologi, religionsvetenskap, religionshistoria och religionsantropologi bär på olika historia i sina framväxter som forskarämnen, och därmed kan olika problemställningar och forskningsfält vara aktuella. I vissa fall delar ämnena också mycket och kan befrukta varandra. Jag vill dock i denna artikel visa på några av de frågor som skiljer sig åt genom att ta avstamp i mötet mellan teologi och religionsantropologi. Anledningen till att jag dryftar att ta upp dessa frågor är att jag precis har läst Anders Klostergaard Petersens mycket kritiska text Nostalgisk elegi eller idylliserende reminiscens af tanken om den æelle vilde, publicerad i Religionsvidenskabeligt Tidsskrift 67 (2018), och som är en review av Mikael Rothsteins forskningsgärning om penanfolket i Regnskovens Religion. Forestillinger og ritualer blandt Borneos sidste jæger-samlere. En religionshistorisk monografi (2016). Petersen radar upp invektiv över Rothsteins forskning: han är inte inläst i viktiga teorier (2018, 161: "kendetegnes ved idiosynkrasi”), han feltolkar teorier eller saknar nödvändig teoribildning (ibid: "forfalder...til en naiv intuitivisme"), och han ägnar sig åt "tribalidyllisering og naturromantik" (ibid.) vilket hindrar penan att få del av "modernitetens herligheder" (ibid.). Listan kan göras lång och i samma mening som Petersen erkänner att ett intresse väckts hos honom av boken, så "har jeg ladet mig irritere af den uvidenhed, skryden og overfladiskhed, som også præger den" (s. 162).

Varför denna hätskhet och detta negativa ordval över ett mycket gediget insamlande av penanfolkets livsvärld? Arbetet har dessutom krävt ett tufft fältarbete med återkommande besök för att följa den nomadiserade folkgruppen i regnskogen, vilket skulle kunna få många antropologer att tveka inför liknande uppdrag och därför finns det inte mycket material om gruppen insamlat. När jag läser mellan raderna ser jag att mycket av kritiken kan finnas i en brist på kännedom hos Petersen att tackla de situationer, kontexter och diskussioner som en antropolog/religionsantropolog kan hamna i.

Jag har själv genomfört fältarbeten, främst hos kanadensiska mi'kmaq och varit på kortare fältvistelser på Tongaöarna samt i Peru (främst Anderna, men även genomresa längs med Amazonfloden). Jag känner från dessa fält igen mig i den problematik Rothstein möter och diskuterar, även om det empiriska materialet varierar. Som fältarbetare och inlästa på det kultur/social/religionsantropologiska forskningsfältet möter vi andra problemställningar, av naturliga skäl också bitvis en annan kanon än vad textstudier använder, och nära möten upprättas, vilket också blir synligt i Rothsteins penanstudier. Engagerad antropologi, reflexivitet hos forskaren om sin roll i synliggörandet av materialet, kulturmötets problematik och maktstrukturer - och idag intresset för den 'nyanimistiska' forskningen - har en annan bärighet och diskussion inom ämnet än de avstamp Petersen tar i sina angreppspunkter av Rothsteins text. Petersen verkar ha sin hemmahörighet i de teologiska ämnena och kan därför av naturliga skäl vara obekant med religionsantropologens vardag och forskningskontext. Jag vet heller inte om den indignation Petersen visar mot Rothsteins angrepp på kristendomen och missionen har att göra med personliga känslor och det Petersen 
menar är orättfärdig kritik av kristen tro. Men tyvärr, när vi som i penans fall talar om kulturmöten med storsamhället, så är det nästan aldrig dessa sker på lika villkor utan det finns maktstrukturer att lyfta fram, inte minst då kolonialismen historiskt gått hand $\mathrm{i}$ hand med missionsiver och missionen fått legitimera varför kolonialismen varit en nödvändighet (Hornborg 2012). Detta visar inte minst ursprungsinvånarnas historia i Nordamerika upp och som idag är fysiskt synligt i reservatssystemet.

Jag tänkte här hålla mig till några av de punkter jag tycker är viktiga att utveckla för att möta Petersens kritik och hans avsaknad av centrala religionsantropologiska diskussioner. Då jag recenserat Rothsteins bok i Chaos 66 (2016: II) och i Hunter Gatherer Research $(2016,2: 4)$ samt att Petersen i sin läsning av samma text kommer till helt andra bedömningar, vill jag utgå från några av hans angreppspunkter och ge andra perspektiv på de brister eller luckor som jag ser i Petersens kritik och text. Huvudpunkter som behandlas är engagerad antropologi, reflexivitet, 'nyanimismen' och religionsbegreppet, samt kristen mission och modernitet som hjälp (utveckling?) eller hot.

\section{Engagerad antropologi och reflexivitet}

Jag vet inte om det är en skröna eller det finns en sanning i att när språkforskaren George Smith i slutet på 1800-talet tydde Gilgameshtexterna och fann till sin stora förtjusning en beskrivning av syndafloden som var äldre än Bibelns, men med stora likheter, blev han så överväldigad av sina känslor att han sprang omkring i rummet och tjoade och hojtade. Det påstås också att när hans kollegor gick för att se vad som hänt, så slet Smith av sig kläderna i ren glädje. ${ }^{1}$ Här kan vi tala om den engagerade forskaren i texternas värld, men att se hur ljuset tänds från en ny lampa över en text är dock annorlunda än att befinna sig i mänskliga livsvärldar, där forskaren ej med lupp och kikare på distans kan betrakta 'studieobjekten'. Universitetet i Cornell (Ithaka, New York) fångar här kärnfullt in religionsantropologins relationella karaktär:

Anthropology is by definition engaged. We work collaboratively with communities around the world to advance human understanding and to contribute constructively to local needs and concerns...we are committed to nurturing courses and collaborations that can provide students with "Field Encounters," which place the experience of being

"in the field" at the heart of the major. ${ }^{2}$

Möten i fält, speciellt under längre tid och med återkommande besök, skapar vänskapsrelationer och engagemang i livsvärldar, men även prövningar. De 'romantiska bilderna' kan plötsligt omkullkastas och antropologen måste ställa nya frågor (Hornborg 2003, 132-133). Ibland kan ambitionen med att nedteckna och dokumentera kännas obekväm, som när vandringarna i reservatsmiljön (med dem som brukar kallas 'informanter' men som blivit vänner med åren), tedrickande, bilturer och McDonaldsbesök plötsligt bryts av med antropologens frågor där relationen riskerar

1 (https://www.nationalgeographic.com/archaeology-and-history/magazine/2018/01-02/history-gilgamesh-epic-discovery/)

2 (http://anthropology.cornell.edu/engaged-anthropology) 
att bli objektifierad i forskningens tjänst. Det är också en medvetenhet antropologen får leva med, att vistelsen och möten i fält inte sker under lika villkor. Förr eller senare sker uppbrott och antropologen ska återföras till den akademiska världen. Att flyttas mellan olika fält, må det vara mellan den akademiska världen och 'informanternas' livsvärld, eller att befinna sig i en livsvärld där vissa begrepp som tidigare känts vardagliga och förnuftiga nu relativiseras i den nya kontexten, skapar en reflexivitet hos antropologen som måste hitta nya ingångar i sina tolkningar och hanterande av materialet:

Reflexivity in anthropology refers to the examination of the ethnographic encounter as a dialogue between individuals and cultures, and its attempt to understand the limitations these subjectivities impose (Bowie, 2000 [2006], 89; se även Scholte 1972, 435).

Den reflexiva antropologin har, som Fiona Bowie uttrycker det, underminerat 'flugan-i-takets' närmande till 'vetenskaplig' observation, där etnografen ser sig själv som en neutral observatör av empiriska fakta (Bowie, 2000 [2006], 89). ${ }^{3}$

Diskussionen om hur fältet synliggörs, vad som nedtecknas, vilken information antropologen får del av och antropologens personliga hållning och position i gruppen, har således problematiserats i forskningen. Vi kan ta som exempel andetro - hur ska antropologen metodologiskt och teoretiskt tackla detta fenomen? Ett alternativ är att inta en ateistisk hållning: att inte tro på andevärldar och sedan beskriva villfarelsen på ett förklarande sätt. Ett annat sätt är att 'go native', att inta ett slags teistiskt förhållandesätt - antropologen bejakar andetron. Båda dessa sätt har avvisats av de flesta forskare och istället har ofta ett agnostiskt förhållningssätt intagits - antropologen tar inte ställning utan försöker att inta ett utanförperspektiv - 'etic' ${ }^{4}$ för att klargöra fenomenet. Men engagemanget och nära relationer skapar ibland en vandring mellan olika perspektiv, där 'objektet' inte bara belyses utan blir till ett subjekt och en relation till antropologen uppstår som påverkar samspelet. Här kan antropologen vandra mellan olika perspektiv, att förneka andar, eller att under fältets hetta bli berörd av andarna. ${ }^{5}$ Droogers och Knippe $(2011,283)$ har i diskussioner som förts om dilemman i fält lyft fram metodologisk ludism som de definierar som ett sätt att bjuda in "fieldworkers to use their human capacity for play by identifying temporarily, in a serious way, with believers' claims of true knowledge". Religionsstudiet med deltagande i fältet gör att forskaren, enligt dem, inte bara möter en kognitiv diskurs utan också en levd, förkroppsligad verklighet. 'Deltagande observation' i fältarbetet kan därför ses som en paradox (eller oxymoron) - hur kan en antropolog både kunna observera (distans) och på samma gång delta (närhet)? Droogers och Knibble är medvetna om detta:

The seemingly paradoxical combination of nearness and distance refers to a way of

3 Se även Pat Caplans erfarenheter av (Bowie 2000 [2006], 89-92) att vara kvinna i fält och hur de intryck som synliggörs vid återkommande fältbesök kan variera beroende på antropologens erfarenheter och position i gruppen.

4 Om etic/emicdebatten, se till exempel Mostowlansky \& Rota, 2016.

5 Se Hornborg 2003, där jag brottas med dessa frågor. 
knowing that in 'objective' positivist science is considered problematic, but from a constructivist point of view can be understood as based on the interaction between the researcher and the people she studies (Droogers \& Knibbe 2011, 286).

Beroende på fältarbetets karaktär och geografiska område har det för en del antropologer inte bara varit omöjligt att inte engagera sig i fältets livsvärld utan även aktivt göra motstånd till storsamhällets övergrepp. Kalavverkning av Amazonas skogar har fått antropologer att arbeta med organisationer som försöker stoppa att gruppers möjligheter till överlevnad i regnskogen omintetgörs. ${ }^{6}$ Ett annat exempel är hur en amerikansk antropolog, som berättade för mig hur han med filmkamera sakligt ville dokumentera häxutdrivning i Afrika, engagerades på ett sätt han inte var förberedd på. Häxutdrivningsriterna drabbade främst äldre kvinnor, som genomgick plågsamma moment, bland annat knivristningar i kroppen, där såren dränktes in med olika salvor och örtblandningar. Under filmningens gång, och med kameralinsens objektifierande och dokumenterande av vad som skedde, väcktes samtidigt inom antropologen en stark empati för kvinnorna och till slut stängde han av kameran. Han kunde inte längre se deras smärta och lidande och än mindre filma detta som ett led i sin forskning. 'Studieobjekten' hade förvandlats till subjekt och därmed upprättade antropologenen relation till det filmade subjektet, och han erfor nu lidande kroppar och inte ett objekt att dokumentera.

Rothsteins bok andas samma engagemang för penanfolket som många andra fältantropologer uppvisar under sina fältvistelse. Detta engagemang anser Petersen inte vara vetenskap och speciellt inte kritiken mot den kristna missionens verkningar. Han tar sin kritiska utgångspunkt i bokens avslutning och ser Rothstein ord som politiska, icke vetenskapliga: “De kristne penaner har lært, at de skal være glade, men deres ansigtsudtryk og deres adfærd fortæller en helt anden historie, som bekræftes af et religionshistorisk blik $(2016,496)$. Petersen medger att han här anar ett engagemang för en livsvärld som brutits ner, men då blir det varken "religionshistorie eller videnskab" utan ett politiskt budskap som inte hör hemma i den akademiska världen $(2018,174)$. Det är svårt att bedöma för någon som Petersen (eller mig) som inte vistats hos penan om Rothstein läser in rätt tolkning, men det kan vara lika politiskt att hävda motsatsen, att det inte finns ett lidande i omflyttningar och skövling av skogar som påverkat gruppens vara. Regnskogen, som förut kunde ses som ren vildmark, har idag blivit högintressant för timmeravverkning och (i Amazonas) nötboskapsuppfödning. Att sådana omställningar inte skulle sätta spår hos urbefolkningar och att detta bör synas i dokumentationen faller inte utanför vetenskapen. Petersens kritik av Rothsteins text kan här bero på en ovana vid den religionsantropologiska disciplinen, där teologen ställs inför andra problem att brottas med än vad som sker i arkivkammarens textstudier och som den engagerade antropologen försöker både att beskriva och reflexivt förhålla sig till när hon eller han kastas in i fältstudiers problematik. I denna rörelse blir det således aktuellt att även de egna erfarenheterna ska diskuteras och visas upp i materialet. Om detta inte visade sig på ett reflexivt sätt i skrivandet och det engagemang som skapas i relationer mellan människor - antropologer

6 t.ex. FUNAI, https://www.survivalinternational.org/about/funai 
och fältet, samt utmaningar att hitta andra, nya ingångar i materialet när vedertagna begrepp inte räcker till - skulle det enligt mig vara ovetenskap eller ses som brister inom religionsantropologisk forskning.

\section{Religion som ett problematiskt begrepp}

Petersen anklagar Rothstein för en bära på en "ahistorisk essentialisering af en anden religion, kristendom", men lyfter vi blicken ser vi att det Rothstein främst metodiskt arbetar med är att ta sin utgångspunkt i penans livsvärld för att hitta nya vägar att diskutera religionsbegreppet i en miljö som så skiljer sig från de traditionella teologiska definitionernas värld, att dessa inte kan användas i studierna. Försöket att fånga in religionsbegreppet i en kontext som inte skiljt ut religionen som ett fält i sig leder till att Petersen menar (161) att Rothstein förfaller "til en naiv intuitivisme, hvor teori er noget, som læses frem af kilderne selv, og kendetegnes ved idiosynkrasi: 'Every man his theory!' " Försöket att utifrån ett biosemiotiskt perspektiv fånga in hur penan avläser regnskogen i sin kosmologi är mer ett försök att situera gruppen i en specifik kontext för att förstå dessa kosologiska modeller än att förfäkta en universell teori som även ska kunna tillämpas på alla jägar-samlarkulturer, eller timmeravverkare och kristna missionärer. Tanken att inte lägga på penan en i förväg färdig teori och stämma av empirin med denna utan försöka att fånga in empirin i nya modeller behöver inte vara ovetenskap. Teorier är inte för alltid gjutna i sten - det skulle vara att falla för essentialisering - utan de måste prövas och omprövas i mötet med fältet. Återigen kan religionsantropologen (och förhoppningsvis teologen) inte tillämpa kulturteorier (om religionens vara) på samma sätt som naturvetenskapsmannen prövar tyngdlagens giltighet med hjälp av experiment och beräkningar för att visa på att samma lagbundenhet råder, det vill säga oavsett om stenen faller hos penan, timmeravverkaren eller den kristna missionen. Människans förmåga att skapa olika kulturella symbolvärldar påverkar den begreppsapparat som i ett fält genererat vissa analysmetoder och teorier men i ett annat fält inte passar in alls. Om vi tar ett exempel från djurens värld så bygger bävrar sina hyddor på liknande sätt oavsett om bävern är en kanadensare eller en värmlänning. Men människans bostad kan variera från en tillfällig plats längs med en vandringsled till en lägenhet på Manhattan. Det finns ingen gemensam mall att avkoda bakom detta bostadsbyggande (och hos dem som avstår att ha en fast boplats), och forskaren måste här arbeta med helt andra angreppssätt för att förstå hur dessa olika vara-i-världen har uppstått. Petersens synsätt att “Teori er, til forskel fra hvad Rothstein hævder, netop et værn mod egen og mere omfattende kulturel (som f.eks. videnskabelig) vanetænkning og fordomsfuldhed" kan därför behöva förfinas. Teorier är situerade i tid och rum och inte minst vad gäller det mänskliga varat. När Durkheim ville visa på de 'elementära formerna av det religiösa livet' valde han australiensiska aboriginer som exempel för att finna ett slags gemensamt mänskligt urtillstånd och en utgångspunkt för religionens ursprungliga vara, då gruppen ansågs leva kvar på ett enkelt stadium i mänsklighetens utveckling. 
Senare tids forskning har visat att just aboriginerna bland annat har ett mycket komplext släktskapssystem, men evolutionära antaganden att de och andra urbefolkningar skulle bära på ett förstadium till senare utvecklingsstadier var vanliga i tidig forskning. Om jägar-samlarsamhällen funnits representerade långt tillbaka i mänsklighetens historia, även innan neolitikum, så betyder inte ens detta att vi kan dra slutsatsen att dagens nomadiska penan hyser samma kosmologier som dessa. Så läser jag inte Rothsteins bok.

Rothstein har med sina fältvistelser hos penanfolket tagit sig an ett fält som på senare år debatterats flitigt, inte minst inom intresset för 'nyanimistisk' forskning, där mycket banbrytande material hämtats från Sydamerika, men även andra platser där jägar-samlarkulturer försöker överleva som spillror i en värld som ständigt hotas av storsamhället. ${ }^{7}$ Ordet neoanimism finns idag myntat som dialog mot Edward Tylors evolutionära tanke att religionen genomgått olika stadier: från animism, polyteism och sedan monoteism, men där animistiska drag skulle finnas kvar som 'survivals' även i modern tid. Det Tylor såg som en primitiv religionsform och felaktig epistemologi hos ('enkla') folkslag har idag av forskare genomlysts på ett annat sätt, inte minst via religionsantropologers fältarbeten. Nurit Bird-David är en av flera forskare som kritiserat den tylorianska föreställning om animism och vill istället se fenomenet som en form av relationell epistemologi: "animistic ideas operate within the context of social practices, with attention to local constructions of a relational personhood and to its relationship with ecological perceptions of the environment" (Bird-David 1999, 67). Till exempel kan fenomenet schamanism genom Bird-David's definition av relationell epistemologi bli ett sätt att studera hur schamanen lär känna objekt (djur) som subjekt, inte att göra subjekt till objekt.

Petersen saknar ett tydligt definierat religionsbegrepp hos Rothstein och ser bara ett "diffused religionsbegreb" (s. 168) visas upp. Men Rothstein visar istället skickligt hur svårt det är att tillämpa begrepp som religion och natur i en kosmologi som inte skiljer på vardagen och 'det heliga' eller av naturliga skäl via nomadlivet inte som den bofaste ser naturen som det som omgärdar bostaden ('kulturen'). Rothstein diskuterar även ingående de begrepp som penan själva använder för att han inte ska bruka våld på materialet. Han ägnar således sidorna 84-90 till just “Det problematiske religionsbegreb" hos de nomadiska penan. Hur ska religion hos dessa definieras när de "ikke udskiller de religiøse kulturelementer som en særlig kategori" (s. 88)? Han stannar vid en arbetsdefinition där "religion" blir definierat som "en ikke-ekspliciteret kosmologi, dvs. et sammenhængende verdensbillede, hvor 'det religiøse' indgår i fuld integration med alt muligt andet, og hvor den religiøse praksis på samme måde er integreret i hverdagens aktiviteter" (ibid.). Petersen ser en självmotsägelse hos Rothstein när denne både påstår att penan inte har ett religionsbegrepp och ändå skriver om deras 'religion'. Men här skjuter nog Petersen sig själv i foten: Rothstein har ju visat på just dessa sidor under rubriken "Det problematiske religionsbegreb" (s. 84) att begreppet 'religion' bär på kulturella och historiska konstruktioner och

Listan kan göras lång av forskare, men en artikel av Bird-David (1999) med tillhörande kommentarer som Rothstein också refererar till, har fått stor spridning. 
försöker så från ett annat perspektiv diskutera skogsandar, inte genom att föra in dem i västerländska kategorier och definitioner av 'andevärldar' utan genom att ta avstamp i den kosmologi som byggts upp ur penans nomadiska livsvärld. Att pressa in en grupps kosmologi i en annan kulturs begrepp vore att göra våld på materialet. Här har Rothstein bland annat hämtat inspiration från Viveros de Castros perspektivismlära och ekosemiotiken, det senare för att se hur regnskogens tecken samspelar med det perspektiv penan tar upp i sitt vara-i-världen (eller "dwelling" som Tim Ingold skrivit om (s. 2000) och som Rothstein refererar till). Att som Petersen avläsa Rothsteins nyttjande av ekosemiotiken som en form av økospiritualitet är också att tillskriva materialet en dimension som inte finns, då även begreppet 'spiritualitet' kan problematiseras på samma sätt som 'religion' hos penan.

Petersen har också synpunkter på vilken forskarkanon som Rothstein borde använda i diskussionen om sitt material. Han radar upp forskare han anses saknas och som skrivit om liknande fenomen/jägar-samlare som Rothstein (Armin Geertz, Philippe Descola, Jeppe Sinding Jensen för att nämna några) men Rothstein har valt andra relevanta forskare (Nurit Bird-David, Eduardo Viveiros de Castro, Tim Ingold t.ex.) och dessutom de som fördjupat sig specifikt i penans livsvärld och som där bidragit till kännedom om gruppen (t.ex. Bernard Sellato, Peter Sercombe, Rodney Needham). Visst kan några forskare saknas, men forskaren måste alltid göra ett urval av en stor grupp presumtiva referenser (här jägar/samlarkulturer) och det som en forskare ser som ett måste $\mathrm{i}$ en studie, kan för en annan forskare resultera i ett annat urval.

\section{Kulturmöten - på lika villkor?}

En annan problematisk fråga är vad som händer i kulturmöten. Rothstein sysslar enligt Petersen med "tribalromantisering" (s. 174) och med att demonisera kristendom och modernitet. Petersen har här svårt att förstå att kulturmöten inte alltid sker på lika villkor, utan maktspel kan innebära att den ena partnern blir förlorare. Dessutom faller Petersen här in i ett gammalt evolutionärt spår, där moderniteten ses som ett högre utvecklingsstadium: "Jeg synes som også Rothstein, at det er et kulturelt tab, når sprog, kulturer og religioner forgår, men det er nu en gang et uafvendeligt evolutionært vilkår. Alternativt skal man, sat på spidsen, fastholde andre folk i deres oprindelige kulturelle livsvilkår" (ibid.). Men penans möte med väst har inte varit ett "uafvendeligt evolutionært vilkår", utan här delar de många urbefolkningars öden de har koloniserats och livsbetingelserna så radikalt förändrats att vi inte talar om evolution utan om kulturella övergrepp, trauman och ekonomisk exploatering (Hornborg 2010). Peterson riktar kritik mot Rothsteins text som han ser:

ender i bedaget tribalidyllisering og naturromantik, hvor penanerne skal fastholdes i deres naturlighed, medens vi andre så kan nyde godt af modernitetens herligheder som f.eks. lav spæd-børnsdødelighed, lang levetid og social sikkerhed livet igennem (s. 161).

Ska vi vara glada för ekoturismen och tacka denna för att den i regnskogens Sydamerika genererat en lönsam turistindustri som ger till exempel witotofolket längs med 
Amazonfloden i Peru chansen att få lite inkomst genom att nu varje vecka visa upp för besökare sin 'traditionella' anakondadans och upplevelsen att se hur en spillra av ett ursprungsfolk fortfarande lever kvar på sitt 'traditionella sätt' i regnskogen, som utan turistströmningen skulle helt skövlats av skogsbolag? Där någon ser framgångsrik utveckling för 'fattiga skogsindianer' ser andra kulturspillror där makten och penningen talat sitt språk.

Petersen hyllning av "modernitetens herligheder" som skulle kunna frälsa penan från det traditionella livet kräver en genomlysning, både historiskt och samtida. Om vi bara lyfter blicken till den nordamerikanska kontinenten så resulterade kulturmötet $i$ att en stor del av urbefolkningen dog ut i epidemier och krigföring. Vad gäller den grupp jag närstuderat, mi'kmaq i östra Kanadas kustlandskap, finns beräkningar på att krigsföring och epidemiska sjukdomar som gruppen saknade immunitet emot, reducerade stammarna enligt vissa forskare med upp till 90\% (Whitehead 1991, 77; Prins 1996, 2; Hornborg 2008, 5). Missionärerna följde tätt kolonialisterna och i deras skrifter kan vi avläsa synen på mi'kmaq, där 'det vilda' kan ses som en nyckelmetafor i bedömningen av både individen, samhället och ekologin (Hornborg 2012). Landskapet, som mi'kmaqnomaderna rörde sig i, beskrevs på 1600-talet som “Satans vildmark" av missionären Pierre Biard och det sågs som en plikt att i det nya landet skapa ett uppodlat landskap likt Edens lustgård (Biard [1616] 1959, 34 -35). Mi'kmaqsamhällets nomadtillvaro liknades vid djurens vandringsleder, gruppen strövade omkring utan förmåga att bygga bostäder liknande kulturmänniskornas (läs kolonialisternas) samhälle. Individens 'vilda' natur skulle tämjas med hjälp av missionen och fasta bosättningar (Biard [1611] 1959, 173), vilket skulle förlösa grupperna också från svält och umbärande i deras kamp med den vilda naturen. Men forskare har idag omprövat de tidiga européernas tanke att nomadlivet innebar en ständig kamp för födan och säger mer om européernas kamp för överlevnad i det nya landet än om mi'kmaqs liv i Kanadas kustprovins (Martin 1992, 48; cf. Sahlins 1972).

Mi'kmaqs möte med européerna var således inte ett jämlikt möte utan utvecklades både till en fysisk kamp om provinsen och om mi'kmaqs själar. Striden om marken vann engelsmännen i hård konkurrens med fransmännen, men själarna gick till katolicismen, ett sista försök att bjuda engelsmännen och den anglikanska kyrkan motstånd. Eftersom nomadlivets ekologiska miljö inte kunde samspela med uppodlad mark, som dessutom privatiserades och utökades med europeiska nybyggare, måste något ge vika och det var mi'kmaqs livsvärld. Nästa steg var att ta sig an 'problemet' med den kringströvande och jagande gruppen. Lösningar som gavs var brutala. Det förekom till och med skottpengar på mi'kmaqskalper. Men för att få slutlig kontroll på gruppen infördes reservatssystemet i mitten av 1800-talet. Ytterligare disciplinering genomfördes i slutet på 1920-talet, då en residential school ${ }^{8}$ byggdes upp i Schubenacadie, i Nova Scotia. Tusentals indianbarn skulle nu assimileras via internatskolan till det kanadensiska storsamhället, de togs från sina hem och tvångsplacerades under sin skoltid, långt från släkt och familj (Hornborg 2010). Skolan, som styrdes av katolska präster och nunnor, stängdes på 1960-talet, men har satt djupa

8 Liknande skolor byggdes upp i hela den nordamerikanska kontinenten. 
spår i reservaten, där även en ny generation talar om sig som andra generationens "survivors", då de vuxit upp i familjer där en eller båda föräldrarna kan ha erfarenheter av internatvistelsen. På youtube kan vi finna ett klipp där internatskolans effekter på mi'kmaqsamhället, där barn rycktes ut ur familj- och släktgemenskapen, mycket drastiskt kallas för "Canadian Holocaust". ${ }^{9}$

Mi'kmaq har idag tillgång till modern sjukvård och teknik, och skulle kunna "nyde godt af modernitetens herligheder" som Petersen skriver, men detta är inte hela sanningen. För det första finns en fattigdom på reservaten och för att njuta av modernitetens goda krävs pengar och arbete. Arbetslösheten är stor på reservaten och mi'kmaq påverkas av allt från sjukdomar (diabetesinsjuknande är högre här än i storsamhället), droger, missbruk och med detta följer våld och psykisk ohälsa. Självmord är vanligt bland unga, både flickor och pojkar. Det är inte ovetenskap att se detta som ett resultat av modernitet, fattigdom och kolonisering där en grupp blivit förlorare i kampen om provinsen (Hornborg 2010). Ska vi idag tacka det moderna samhället för att det kan ge mi'kmaq psykofarmaka när reservatssystemet och fattigdom genererar psykisk ohälsa?

\section{Att "läsa" livsvärldar}

Petersen och jag må vara eniga om att läsarreceptionen av en och samma text kan se olika ut. Vad gäller läsningen av Rothsteins bok kommer vi till helt olika slutsatser om texten. Där jag ser en engagerad forskare med en reflexiv hållning till det som upplevs och nertecknas i fält, ser Petersen ovetenskap och en politisk agenda. Där jag ser en sofistikerad studie och noggrann genomlysning av ett (religions)begrepp som problematiseras i kontextualiseringen, ser Petersen en avsaknad av diskussion och teoribildning. Där jag läser om kulturmöten och maktpositioner ser Petersen ett orättfärdigt påhopp av modernitet och kristen mission. Kolonialisering och mötet med Västerlandet, missionen och senare den moderna tekniken vill jag därför sätta i relation till maktperspektiv och ekonomiska intressen. Det som benämns evolution följer inte naturvetenskapens utvecklingslagar utan kan för vissa grupper innebära umbärande som än idag påverkar livsvillkoren, vilket är synligt i till exempel det nordamerikanska reservatssystemet. Att kalla detta 'utveckling' (evolutionärt tänkande) ser jag som orättfärdigt och att analysera dessa förhållanden där maktförhållanden blir synliga innebär inte en romantisering av det som varit, eller en beskrivning av 'den ädle vilden', men en nödvändig samhälls- och kulturanalys av det fält antropologen befinner sig i.

Mina kommentarer på Petersens text har varit ett försök att lyfta diskussionen som förs om Rothsteins text och visa hur religionsantropologin och fältstudier bidrar med viktig kunskap om människors livsvärldar och det som i både Petersens och min värld kan sammanfattas under ämnet religionsvetenskap. En öppenhet för det religi-

9 http://www.youtube.com/watch?v=hqPIh-267fg 
onsantropologiska ämnets bidrag till religionsforskning - engagerad antroplogi, reflexivitet, samt kulturmötesanalyser, ser jag inte bara som önskvärt utan som en nödvändighet för fördjupning om olika gruppers vara-i-världen.

\section{LITTERATUR}

Biard, Pierre

1959 "Relation de la Nouvelle France" [1616], in: Thwaites, ed., översatt av John Covert, The Jesuit Relations and Allied Documents, vol. III, Pageant Book, New York, 26- 301.

Bird-David, Nurit

1999 “'Animism' Revisited: Personhood, Environment, and Relational Epistemology”, Current Anthropology 40, 67-79. https://doi.org/10.1086/200061

Bowie, Fiona

2000 The Anthropology of Religion: An Introduction [2006], Blackwell.

Droogers, André och Kim Knibbe

2011 "Methodological Ludism and the Academic Study of Religion", Method and Theory in the Study of Religion 23, 283-303.

Hornborg, Anne-Christine

2003 "Being in the Field: Reflections on a Mi'kmaq Kekunit Ceremony", Anthropology and Humanism 28 (2), 1-13. https://doi.org/10.1525/ahu.2003.28.2.125

2008 Mi'kmaq Landscapes: From Animism to Sacred Ecology, Routledge.

2010 “Cultural Trauma, Ritual and Healing", i Göran Collste, red., Identity and Pluralism: Ethnicity, Religion and Values, Studies in Applied Ethics nr. 12, LIU-tryck, Linköpings universitet: http://liu.diva-portal.org/smash/record.jsf?pid=diva2:355027, 104-119.

2012 "Making a Garden out of the Wilderness: contested ideas of landscape, dwelling and personhood in the encounter between European settlers and the Mi'kmaq in 'New France' ", in: Laura Feldt, ed., , Wilderness in Mythology and Religion: Approaching Religious Spatialities, Cosmologies, and Ideas of Wild Nature, Religion and Society Series vol. 55, de Gruyter, 205-228. https://doi.org/10.1515/9781614511724.205

2016a "Mikael Rothstein: Regnskovens Religion. Forestillinger og ritualer blandt Borneos sidste jægersamlere. En religionshistorisk monografi" (review), Chaos 66, 181-183.

2016b "Mikael Rothstein: Regnskovens Religion. Forestillinger og ritualer blandt Borneos sidste jægersamlere. En religionshistorisk monografi" (review), Hunter Gatherer Research 2 (4), 483-486. https://doi.org/10.3828/hgr.2016.32

Ingold, Tim

2000 The Perception of the Environment: Essays in Livelihood, Dwelling and Skill, Routledge.

Martin, Calvin

1992 In the Spirit of the Earth: Rethinking History and Time, The John Hopkins University Press.

Mostowlansky, Till \& Andrea Rota

2016 "'A Matter of Perspective?' Disentangling the Emic-Etic Debate in the Scientific Study of Religion $\backslash \mathrm{s}^{\prime \prime}$, Method and Theory in the Study of Religion 28, 317-336. https://doi.org/10.1163/15700682-12341367

Petersen, Anders Klostergaard

2018 "Nostalgisk elegi eller idylliserende reminiscens af tanken om den ædle vilde", Religionvidenskabeligt Tidskrift 67, 161-175. https://doi.org/10.7146/rt.v0i0.104438

Prins, Harald E. L.

1996 The Mi'kmaq. Resistance, Accommodation, and Cultural Survival, Harcourt Brace \& Company.

Rothstein, Mikael

2016 Regnskovens religion. Forestillinger og ritualer blandt Borneos sidste jæger-samlere. En 
religionshistorisk monografi, U Press, Köpenhamn.

Sahlins, Marshall D.

1972 Culture and Practical Reason, University of Chicago Press.

Scholte, Bob

1972 "Toward a reflexive and critical anthropology", In: Dell Hymes, ed, Reinventing Anthropology, Pantheon books, University of Michigan, 430-457.

Whitehead, Ruth Holmes

1991 The Old Man Told Us, Nimbus, Halifax.

\section{INTERNET}

“Canadian Holocaust": http://www.youtube.com/watch?v=hqPIh-267fg (tillgänglig 2018-05-11)

https://www.nationalgeographic.com/archaeology-and-history/magazine/2018/01-02/historygilgamesh-epic-discovery/ (tillgänglig 2018-05-11)

https://www.survivalinternational.org/about/funai (tillgänglig 2018-05-11)

Anne-Christine Hornborg, Professor in History of Religions

Lund University, Centre for Theology and Religious Studies 